\title{
Catalysts for the Controlled Polymerization of Conjugated Dienes
}

\author{
Marc Visseaux \\ UMR 8181-UCCS—Unité de Catalyse et de Chimie du Solide, ENSCL, Centrale Lille, University Artois, \\ University Lille, CNRS, F-59000 Lille, France; marc.visseaux@ensc-lille.fr
}

Received: 5 October 2018; Accepted: 7 October 2018; Published: 9 October 2018

\section{Background}

Since its first discovery at the beginning of the 1960s [1], the coordinative polymerization of conjugated dienes has improved continuously, performer better and better. Today, chemists know how to stereospecifically polymerize conjugated dienes, whether in 1,4-cis, 1,4-trans, or 3,4(1,2) fashion. The petro-sourced (nowadays also bio-sourced for a number of them) butadiene, isoprene, and substituted conjugated diene monomers have been the subject of a very large number of studies in this context, more recently joined by natural dienes from the terpene family such as myrcene, farnesene, and ocimene. The industry has greatly helped to improve the performances of the catalytic systems (activity/productivity, selectivity, efficiency in metal catalyst), with the aim of optimizing the preparation of synthetic polymers such as 1,4-cis polybutadiene, which are widely applied in the tires, rubbers, and combined styrene-based resins (ABS, HIPS). Catalysts today cover a wide set of elements among which are metals from groups 4-6, 8-10 [2,3], and rare earths [4-6], while, to date, industrial concerns are mainly dominated by four metallic elements-namely neodymium, nickel, cobalt, and titanium [7]. For the synthesis of 1,4-cis polybutadiene, the industry catalysts are generally based on ternary systems, with a pre-catalyst associated to an activator and an aluminum chain transfer agent. The 1,4-trans polydienes are rather synthesized either by means of binary catalytic systems often comprising an alkylmagnesium cocatalyst, or by combination with an aluminum derivative in the case of transition metal systems. The 3,4-polydienes do not exist in the natural state, their preparation was synthetically developed later, and they have recently been shown to be potentially useful for improving tire performance, thanks to their excellent skid resistance and their low rolling resistance [8]. Nowadays, there is a better understanding of the polymerization mechanism and involves allyl-active species, thanks in particular to the support of more and more efficient calculations methods [9-11]. Since the beginning of the 2000s, there has also been a tendency for statistical copolymerization of 1,3-dienes with olefin or styrene comonomers to produce statistical, alternating, and block copolymers [12], while access to multiblock and stereoblock copolymers is currently made possible by the innovative approaches of coordinative chain transfer polymerization [13]. A last challenge is about to be solved with the preparation of stereoregular polydienes (and their copolymers) that are also end-functionalized, thanks to the living character of the polymerization. Finally, the future will probably see the development of alternative catalysts made from non-toxic and abundant metals like iron, while an even greater interest can be expected for rare earth catalysts following the discovery of new geological resources of these elements [14].

This issue brings together several important aspects of this chemistry, which remains at the forefront of both academic and industrial research interests. 


\section{The Present Issue}

I would like to thank all of the authors and reviewers for contributing to this special issue, which together makes a nice collection of studies. I would also like to thank the editorial team and the Editor-in-Chief for their efforts in putting this issue together.

This issue comprises six research papers (five articles and one mini-review).

In the first article, Anwander and coworkers propose a global study on the use of homoleptic rare earth tetramethylaluminates for the polymerization of conjugated dienes, including a large number of rare earths elements. Activation pathways with boron derivatives and catalytic combination with $\mathrm{AlEt}_{2} \mathrm{Cl}$, for isoprene and butadiene, result in the synthesis of highly 1,4-cis stereoregular polymers. This study also proposes advances in reaction mechanisms, with a difference between butadiene and isoprene. The syntheses of the pre-catalysts are optimized with the X-ray structure of two of them based on gadolinium and terbium [15].

The second contribution is from the group of Ricci. Allyl cobalt phosphine complexes were prepared and characterized, they polymerized conjugated dienes (including substituted ones) via stoichiometric MAO activation. Particular behavior was observed vs. polymerization, related in particular to the internal or external substitution of the substrate diene monomer, also depending on the molecular structure (exo-exo or exo-endo orientation of the allyl group and steric bulk of additional phosphine ligands) of the pre-catalyst. Hypotheses were given to account for these observations [16].

Ricci and coworkers also contributed with a paper where a family of new trichlorobisphosphino vanadium complexes, where the phosphines were monodentate and tertiary with variations of the phosphine substituents, were used as pre-catalysts for butadiene polymerization. When such compounds were combined with MAO and TMA-free MAO, they resulted in active catalysts. The microstructure of the polybutadienes isolated was tentatively rationalized in terms of molecular structure of the pre-catalysts (better catalytic activity with lower basicity of the phosphine ligands). However, no marked differences were noted regarding the selectivity of the polymerization. This is the first example of the use of $\mathrm{VCl}_{3}$ (bisphosphine) complexes for butadiene polymerization [17].

In the fourth article, from J.-F. Carpentier and co-workers, the copolymerization of bio-renewable $\beta$-myrcene or $\beta$-farnesene with styrene was examined using an ansa-neodymocene catalyst, affording two series of copolymers with high styrene content and unprecedented syndioregularity of the polystyrene sequences. The incorporation of terpene in the copolymers ranged from 5.6 to $30.8 \mathrm{~mol} \%$ ( $\beta$-myrcene) and from 2.5 to $9.8 \mathrm{~mol} \%$ ( $\beta$-farnesene), respectively. NMR spectroscopy and DSC analyses suggested that the microstructure of the copolymers consists of 1,4- and 3,4-poly(terpene) units statistically distributed along the syndiotactic polystyrene chains. The thermal properties of the copolymers are strongly dependent on the terpene content, which is controlled by the initial feed. The terpolymerization of styrene with $\beta$-myrcene in the presence of ethylene was also examined [18].

The fifth article, from the group of Tanaka, was dealing with the elaboration of stereodiblock polymer of butadiene. In the first part of the study, butadiene polymerization was achieved in both a highly cis- or trans-specific manner, by using a $\mathrm{Cp}^{*} \mathrm{Nd}\left(\mathrm{BH}_{4}\right)_{2}(\mathrm{THF})_{2}-\mathrm{Bu}_{2} \mathrm{Mg}$-d-MMAO system (d-MMAO for trialkylaluminum-depleted modified methylaluminoxane) as an initiator. This additional $\mathrm{Al}$ cocatalyst was added in variable amounts at the beginning of the polymerization and the cis-/trans- ratio could be tuned by the quantity of d-MMAO. The absence of termination or chain transfer reaction during the polymerization, deduced from the regular increase of $\mathrm{Mn}$ with the polymer yield, allowed further the synthesis of stereodiblock polybutadiene. This was achieved by adding dMMAO in a second time, to a polymerization mixture firstly initiated with $\mathrm{Cp}^{*} \mathrm{Nd}\left(\mathrm{BH}_{4}\right)_{2}(\mathrm{THF})_{2}-\mathrm{Bu}_{2} \mathrm{Mg}$ [19]. The stereodiblock polybutadiene thus synthesized displayed higher cis-regularity of the polydiene sequence, along with a broader difference of $\mathrm{Tm}$ and $\mathrm{Tg}$ temperatures, compared with the cis/trans- stereodiblock polyisoprene reported previously using a $\mathrm{Nd} / \mathrm{Mg} / \mathrm{Al}$ combined catalyst system based on $\mathrm{Nd}\left(\mathrm{BH}_{4}\right)_{3}(\mathrm{THF})_{3}$ [20].

Finally, our group contributed under the form of a mini-review, which focuses on the recent advances on the synthesis, structure, and characterization of allyl-based rare earth organometallic 
complexes, with emphasis on their ability to catalyze the polymerization of non-polar monomers such as conjugated dienes, styrene, and their related copolymerization [21].

\section{References}

1. Thiele, S.K.H.; Wilson, D.R. Alternate Transition Metal Complex Based Diene Polymerization. J. Macromol. Sci. C Polym. Rev. 2003, 43, 581-628. [CrossRef]

2. Ricci, G.; Sommazzi, A.; Masi, F.; Ricci, M.; Boglia, A.; Leone, G. Well-defined transition metal complexes with phosphorus and nitrogen ligands for 1,3-dienes polymerization. Coord. Chem. Rev. 2010, 254, 661-676. [CrossRef]

3. Takeuchi, D. Stereoselective Polymerization of Conjugated Dienes. In Encyclopedia of Polymer Science and Technology; John Wiley \& Sons: Hoboken, NJ, USA, 2013.

4. Fischbach, A.; Anwander, R. Rare-Earth Metals and Aluminum Getting Close in Ziegler-Type Organometallics. Adv. Polym. Sci. 2006, 204, 155-281.

5. Friebe, L.; Nuyken, O.; Obrecht, W. Neodymium-Based Ziegler/Natta Catalysts and their Application in Diene Polymerization. Adv. Polym. Sci. 2006, 204, 1-154.

6. Zhang, Z.; Cui, D.; Wang, B.; Liu, B.; Yang, Y. Polymerization of 1,3-Conjugated Dienes with Rare-Earth Metal Precursors. Struct. Bond. 2010, 137, 49-108.

7. Srivastava, V.K.; Maiti, M.; Basak, G.C.; Jasra, R.V. Role of catalysis in sustainable production of synthetic elastomers. J. Chem. Sci. 2014, 126, 415-427. [CrossRef]

8. Yao, C.; Liu, D.; Li, P.; Wu, C.; Li, S.; Liu, B.; Cui, D. Highly 3,4-Selective Living Polymerization of Isoprene and Copolymerization with $\varepsilon$-Caprolactone by an Amidino $\mathrm{N}$-Heterocyclic Carbene Ligated Lutetium Bis(alkyl) Complex. Organometallics 2014, 33, 684-691. [CrossRef]

9. Guo, H.L.; Bi, J.F.; Wu, Q.Y.; Wang, J.Y.; Shi, W.Q.; Zhang, X.Q.; Jiang, S.C.; Wu, Z.H. In situ X-ray absorption fine structure study on the polymerization of isoprene assisted by Nd-based ternary catalysts. RSC Adv. 2017, 7, 14413-14421. [CrossRef]

10. Kang, X.; Luo, Y.; Zhou, G.; Wang, X.; Yu, X.; Hou, Z.; Qu, J. Theoretical Mechanistic Studies on the trans-1,4-Specific Polymerization of Isoprene Catalyzed by a Cationic La-Al Binuclear Complex. Macromolecules 2014, 47, 4596-4606. [CrossRef]

11. Kefalidis, C.E.; Castro, L.; Perrin, L.; Del Rosal, I.; Maron, L. New perspectives in organolanthanide chemistry from redox to bond metathesis: Insights from theory. Chem. Soc. Rev. 2016, 45, 2516-2543. [CrossRef] [PubMed]

12. Huang, J.; Liu, Z.; Cui, D.; Liu, X. Precisely Controlled Polymerization of Styrene and Conjugated Dienes by Group 3 Single-Site Catalysts. Chem CatChem 2018, 10, 42-61. [CrossRef]

13. Valente, A.; Mortreux, A.; Visseaux, M.; Zinck, P. Coordinative Chain Transfer Polymerization. Chem. Rev. 2013, 113, 3836-3857. [CrossRef] [PubMed]

14. Takaya, Y.; Yasukawa, K.; Kawasaki, T.; Fujinaga, K.; Ohta, J.; Usui, Y.; Nakamura, K.; Kimura, J.-I.; Chang, Q.; Hamada, M.; et al. The tremendous potential of deep-sea mud as a source of rare-earth elements. Sci. Rep. 2018, 8, 5763. [CrossRef] [PubMed]

15. Hollfelder, C.O.; Jende, L.N.; Diether, D.; Zelger, T.; Stauder, R.; Maichle-Mössmer, C.; Anwander, R. 1,3-Diene Polymerization Mediated by Homoleptic Tetramethylaluminates of the Rare-Earth Metals. Catalysts 2018, 8 , 61. [CrossRef]

16. Ricci, G.; Boccia, A.C.; Leone, G.; Forni, A. Novel Allyl Cobalt Phosphine Complexes: Synthesis, Characterization and Behavior in the Polymerization of Allene and 1,3-Dienes. Catalysts 2017, 7, 381. [CrossRef]

17. Leone, G.; Zanchin, G.; Pierro, I.; Sommazzi, A.; Forni, A.; Ricci, G. Synthesis, Structure and 1,3-Butadiene Polymerization Behavior of Vanadium(III) Phosphine Complexes. Catalysts 2017, 7, 369. [CrossRef]

18. Laur, E.; Welle, A.; Vantomme, A.; Brusson, J.-M.; Carpentier, J.-F.; Kirillov, E. Stereoselective Copolymerization of Styrene with Terpenes Catalyzed by an Ansa-Lanthanidocene Catalyst: Access to New Syndiotactic Polystyrene-Based Materials. Catalysts 2017, 7, 361. [CrossRef]

19. Tanaka, R.; Shinto, Y.; Nakayama, Y.; Shiono, T. Synthesis of Stereodiblock Polybutadiene Using $\mathrm{Cp}^{*} \mathrm{Nd}\left(\mathrm{BH}_{4}\right)_{2}(\text { thf })_{2}$ as a Catalyst. Catalysts 2017, 7, 284. [CrossRef] 
20. Tanaka, R.; Yuuya, K.; Sato, H.; Eberhardt, P.; Nakayama, Y.; Shiono, T. Synthesis of stereodiblock polyisoprene consisting of cis-1,4 and trans-1,4 sequences by using a neodymium catalyst: Change of the stereospecificity triggered by an aluminum compound. Polym. Chem. 2016, 7, 1239. [CrossRef]

21. Jothieswaran, J.; Fadlallah, S.; Bonnet, F.; Visseaux, M. Recent Advances in Rare Earth Complexes Bearing Allyl Ligands and Their Reactivity towards Conjugated Dienes and Styrene Polymerization. Catalysts 2017, 7, 378. [CrossRef]

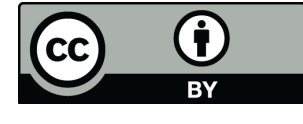

(C) 2018 by the author. Licensee MDPI, Basel, Switzerland. This article is an open access article distributed under the terms and conditions of the Creative Commons Attribution (CC BY) license (http://creativecommons.org/licenses/by/4.0/). 